\title{
Anomalous origin of the right pulmonary artery from the ascending aorta: results of direct implantation surgical repair in 6 infants
}

\author{
Li Xie, Lei Gao, Qin Wu, Can Huang, Jin-Fu Yang, Tian-Li Zhao, Zhong-Shi Wu and Yi-Feng Yang*
}

\begin{abstract}
Background: Anomalous origin of the right pulmonary artery from the ascending aorta (AORPA) is a rare and potential fatal kind of congenital heart disease. This study summarizes the techniques and outcomes of 6 infants with AORPA who underwent the surgical repair.

Methods: Between November 2012 and November 2014, 6 infants with AORPA received surgical repair in the Second Xiangya Hospital and were included in the present study.

Results: Six infants ( 4 male, $66.7 \%$ ) with a median age of $101.5 \pm 70.0$ days, and a median body weight of $4.13 \pm$ $0.62 \mathrm{~kg}$ underwent the surgical repair at our institute. There were no operative, in-hospital or follow-up deaths. Clinical symptoms of all 6 patients relieved at time of discharge, and mean pulmonary artery pressure (MPAP) decreased significantly after surgery. During follow-up, there were no further operations or interventions, mild stenosis at the anastomotic site presented in one patient, and all patients were asymptomatic and in stable clinical condition.

Conclusions: The short and mid-term surgical outcomes of AORPA are excellent in this group of operations. Moreover, we believe the direct implantation to be the optimal surgical strategy for the patients with the proximal form of AORPA.
\end{abstract}

Keywords: Anomalous origin of the right pulmonary artery from the ascending aorta, Infant, Direct implantation, Pulmonary hypertension

\section{Background}

Anomalous origin of the right pulmonary artery from the ascending aorta (AORPA) is a rare and potentially fatal kind of congenital cardiovascular anomaly, and frequently accompanied with other abnormalities, such as patent ductus arteriosus (PDA), Tetralogy of Fallot (TOF), atrial septal defect (ASD), ventricular septal defect (VSD), and aortic arch isthmus hypoplasia [1]. AORPA is classified into two subgroups according to the morphological features: proximal and distal forms $[2,3]$. In the proximal form, the anomalous PA arises proximally from the posterior or left posterior aspect of the ascending aorta close to the aortic valve. About $85 \%$ AORPA are regarded as the proximal form in the report of Kutsche and Van Mierop [3]. In the distal form, the

\footnotetext{
* Correspondence: yyf627@163.com

Department of Cardiothoracic Surgery, The Second Xiangya Hospital of Central South University, Changsha, Hunan Province, China
}

anomalous PA originates from the ascending aorta just proximal to the innominate artery or from the base of the artery itself. The pathophysiological characteristic change of AORPA is early and rapid development of pulmonary hypertension, and which the several mechanisms involve in. These include (1) circulating vasoconstrictor substances, (2) neurogenic crossover from the unprotected lung to the protected one, (3) the development of pulmonary hypertension secondarily after left ventricular failure [4]. Clinical symptoms (tachypnea, recurrent pneumonia, heart failure, etc.) present in most patients during infancy [5]. Without receiving surgical correction, the patients have less chance to survive to adulthood. Once the diagnosis of AORPA is confirmed, the patients should receive surgical treatment as soon as possible. In this study, we summarize the early and mid-term outcomes of 6 patients with AORPA who 
underwent a successful one-stage surgical correction at our institution in last 2 years.

\section{Methods}

\section{Patients}

Between November,2012 and November,2014, 6 patients (4 boys and 2 girls) with AORPA underwent surgical treatment at Xiangya Second Hospital. These patients aged from 30 to 221 days (mean, $101.5 \pm 70.0$ days), with weights from 3.2 to $5 \mathrm{~kg}$ (mean, $4.13 \pm 0.62 \mathrm{~kg}$ ). The detailed information of these patients is shown in Table 1.

The cardiac function, associated anomalies and pulmonary hypertension of the patients were assessed by echocardiography and computed tomography angiography (Figs. 1 and 2). With permission of from the ethics committee of the Second Xiangya Hospital, patient files were reviewed to document clinical presentations, ICU period, operative procedures, perioperative course, and surgical complications, etc. (Table 1). The right pulmonary artery of all patients originated from the right or posterior aspect of the proximal ascending aorta (Fig. 3a). Associated anomalies were observed in all 6 patients (Table 1).

Patient 4, a 33-day-old boy, was treated by mechanical ventilation and was in critical condition when transferred to our hospital from another institute.

\section{Operative techniques}

The surgical approach in all cases was via median sternotomy. In Patient 4, massive pericardial effusion was observed during surgery. The ascending aorta, the right pulmonary artery originating from it, main PA and its branches were carefully mobilized. To establish cardiopulmonary bypass, ascending aortic and bicaval cannulations were implemented, and mild hypothermic cardiopulmonary bypass maintained. Cardiac arrest was used in Patient 2, 3 and 4, and after aortic crossclamping and occlusion of the right pulmonary artery, cold crystalloid cardioplegic solution was perfused through aortic root. Patient 1,5 and 6 underwent the same surgical techniques and procedure but without cardiac arrest. After placing a side-biting clamp on the ascending aorta, the origin of the RPA was dissected and sutured. The right pulmonary artery was anastomosed end to side with the right lateral aspect of the main pulmonary artery (Fig. $3 \mathrm{~b}$ ). CPB time and aortic cross-clamping time were shown in Table 1.

Associated procedures included PDA ligation and dissection in all 6 patients, and the closure of PFO or ASD in 3 patients. Patient 5 has a $2 \mathrm{~mm}$ muscular VSD. Due to the difficulty in locating this VSD, and the insignificance of the left to right shunt, the lesion was not repaired.

\section{Results}

There were no hospital deaths. All patients received elective inotrophic support as needed. The sternum of Patient 4 remained open for 2 days, because of the severe myocardial edema at postoperative day 1. Two days later, the patient was in stable condition and underwent sternal closure and was weaned from mechanical ventilation at postoperative day 4 . In the remaining 5 patients, the postoperative course was uneventful.

The durations of postoperative mechanical ventilatory support time and ICU stay were shown in Table 1. All patients received postoperative echocardiography in

Table 1 In-hospital data of all 6 patients

\begin{tabular}{|c|c|c|c|c|c|c|}
\hline \multirow[t]{2}{*}{ Variable } & \multicolumn{6}{|c|}{ Patient Number } \\
\hline & 1 & 2 & 3 & 4 & 5 & 6 \\
\hline Age(days) & 100 & 104 & 30 & 33 & 121 & 221 \\
\hline Weight(kg) & 4 & 5 & 4.5 & 3.2 & 4.3 & 3.8 \\
\hline Sex & M & M & M & M & $\mathrm{F}$ & $\mathrm{F}$ \\
\hline Type & Proximal & Proximal & Proximal & Proximal & Proximal & Proximal \\
\hline Symptoms & $\begin{array}{l}\text { Tachypnea } \\
\text { cyanosis }\end{array}$ & $\begin{array}{l}\text { Tachypnea } \\
\text { cyanosis }\end{array}$ & $\begin{array}{l}\text { Tachypnea } \\
\text { cyanosis }\end{array}$ & $\begin{array}{l}\text { Tachypnea } \\
\text { cyanosis }\end{array}$ & $\begin{array}{l}\text { Tachypnea } \\
\text { cyanosis }\end{array}$ & $\begin{array}{l}\text { Tachypnea } \\
\text { cyanosis }\end{array}$ \\
\hline Associated anomalies & PDA,PFO & PDA & PDA,PFO & PDA,ASD & PDA,VSD & PDA \\
\hline MPAP $(\mathrm{mmHg})$ & 60 & 52 & 55 & 40 & 46 & 60 \\
\hline CPB time (minutes) & 51 & 69 & 39 & 65 & 111 & 58 \\
\hline Clamping time(minutes) & N/A & 43 & 23 & 23 & N/A & $\mathrm{N} / \mathrm{A}$ \\
\hline $\begin{array}{l}\text { Mechanical ventilation } \\
\text { (hours) }\end{array}$ & 62 & 46 & 88 & 96 & 75 & 27 \\
\hline ICU stay (days) & 7 & 5 & 6 & 14 & 12 & 5 \\
\hline Hospital stay(days) & 38 & 19 & 17 & 25 & 28 & 30 \\
\hline
\end{tabular}



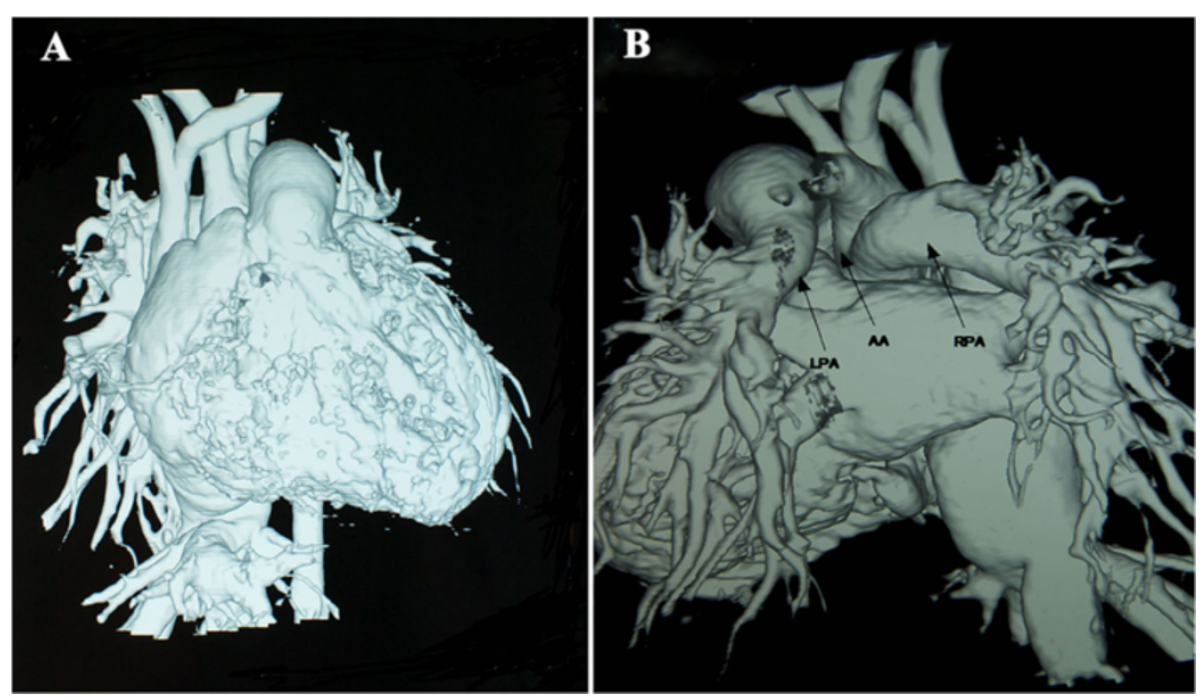

Fig 1 Preoperative CT angiography of Patient 2 identified the anomalous origin of the right pulmonary artery from the ascending aorta; a the antero-posterior VR. $\mathbf{b}$ the postero-anterior VR. AA: ascending aorta, LPA: left pulmonary artery, RPA: right pulmonary artery

hospital (Fig. 4), and median pulmonary artery pressure (MPAP) decreased significantly (Tables 1 and 2).

All 6 patients were discharged in good condition with clinical symptoms relieved. The mean hospital stay was $26.2 \pm 7.7$ days.

\section{Follow-up}

There were no deaths or reoperations during the follow-up. Complete clinical and echocardiographic data were obtained for all 6 patients. Follow-up periods ranged from 2 months to 2 years and were $100 \%$ complete. All patients were alive, asymptomatic, and in stable clinical condition at the most recent follow-up, and to assess the cardiac function, Ross modified score $[6,7]$ was recorded and shown in Table 2 . None has

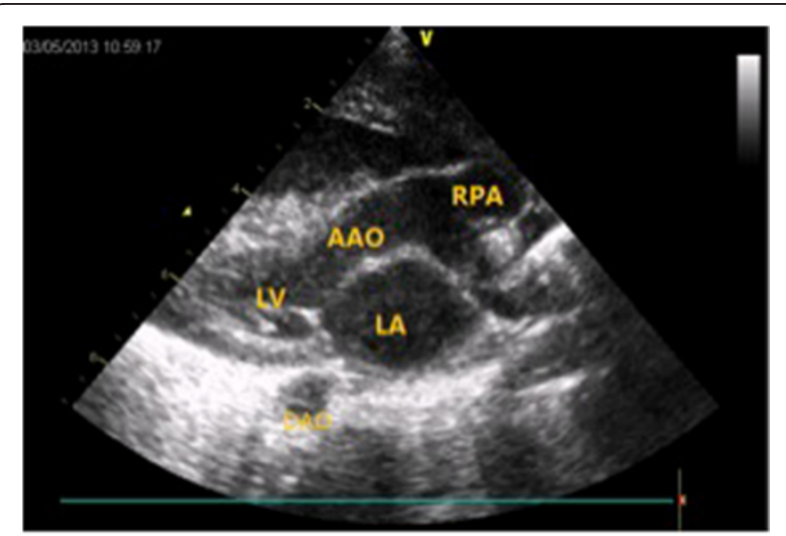

Fig 2 Preoperative echocardiograghy of Patient 3 showed that the right pulmonary artery arose from the ascending aorta. LA: left atrium, LV: left ventricle, AAO: ascending aorta, RPA: right pulmonary artery, DAO: descending aorta required reintervention. The systemic saturation is between $95 \%$ and $100 \%$ in all patients. The latest echocardiographic data are shown in Table 2, and all patients had normal ventricular function with no significant tricuspid regurgitation. The pressure gradient at the anastomotic site of the right pulmonary artery and main pulmonary artery is shown in Table 2. Mild pulmonary stenosis was observed in one patient, with a pressure gradient across the anastomotic site $38 \mathrm{mmHg}$ (Table 2).

\section{Discussion}

The anomalous origin of the right pulmonary artery from the ascending aorta is a subtype of the anomalous origin of one pulmonary artery branch from the ascending aorta. The percent of AORPA occupies less than $0.1 \%$ of congenital heart disease $[3,8]$. In this study, the most commonly associated anomaly was PDA, consistent with a previous report [2]. Moreover, we found no distal form of AORPA in any of 6 patients. This finding was in line with previous findings that the proximal form is five to six times more common than the distal [3].

It has been indicated that histological features of pulmonary vascular disease can be seen as early as the first month of life with AORPA [9]. One-year survival of anomalous origin of one pulmonary artery from the aorta is about $30 \%$ when surgical treatment absent [5]. To avoid pulmonary vascular disease and improve the outcome, AORPA must be repaired as early in life as possible [10-12]. Prifti E et al. [13] has reported that more than $60 \%$ of the patients who had surgery for this anomaly were younger than 6 months at the time of 


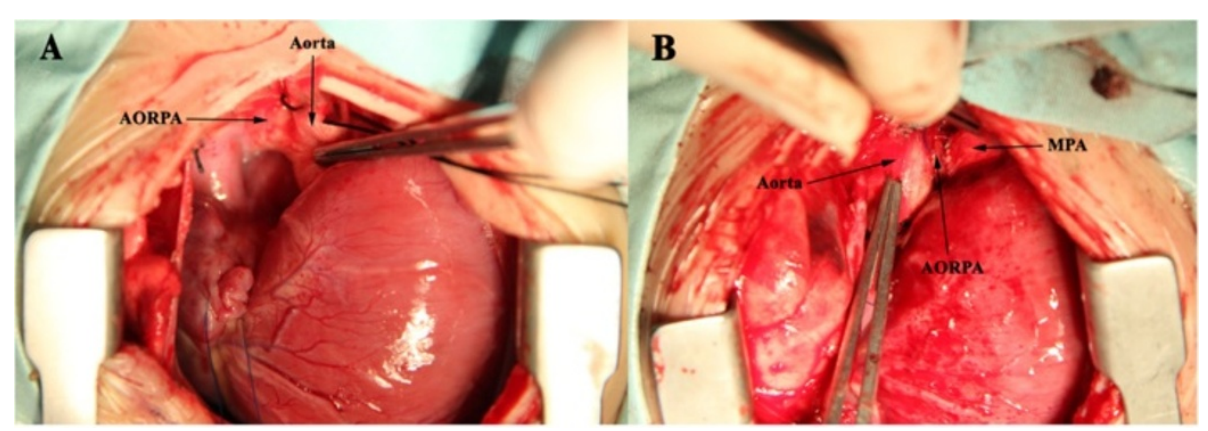

Fig 3 Operative view of Patient 2; a The right pulmonary artery (RPA) originated from the right posterior aspect of the ascending aorta. $\mathbf{b}$ The right pulmonary artery (RPA) was anastomosed to the main pulmonary artery (MPA) by direct implantation

operation. Similar situation happened in our patients, all of which were under 5 months at operation except one.

Since the first successful surgical correction of AORPA was reported in 1961 [14], various surgical techniques have been proposed for reconnection of the right pulmonary artery with the main pulmonary artery. These include implantation using an autologous pericardial patch, graft or homograft interposition and direct implantation [10, 13, 15-17]. Considering the growth potential of the pulmonary artery and the prevention of anastomotic obstruction, the direct implantation-direct anastomosis of the anomalous pulmonary artery to the

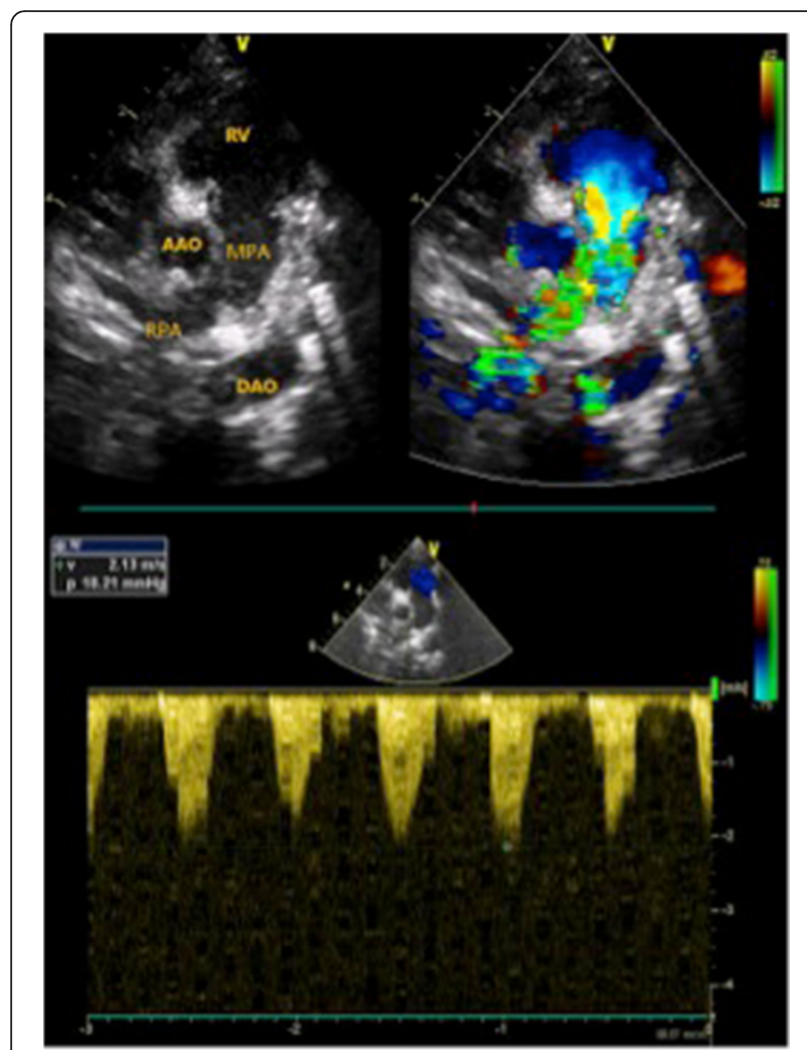

Fig 4 Postoperative echocardiography of Patient 6 pulmonary trunk- seems to be the preferred procedure if it can be achieved without tension $[12,16]$. In our series, direct implantation was employed in all 6 patients after careful and adequate mobilization of the anomalous right pulmonary artery. In our experience, direct implantation always should be implemented in patients with the proximal form of AORPA if it can be achieved without tension.

Patients with AORPA who experienced surgical treatment early in life have excellent short-and longterm outcome [18]. However, the most common late complication after surgical treatment is stenosis at the anastomotic site. Significant stenosis requiring further intervention is regarded as an important cause of morbidity. Peng et al. [18] reported that one of six AORPA patients underwent the reoperation to relieve the anastomotic stenosis. Similar results can be seen in another report [2]. In our patients, there was no significant stenosis requiring reoperation or reintervention during the follow-up. We infer that the rate of stenosis at the anastomotic site is not more than $20 \%$. Due to the small number of the patients, the incidence of anastomotic stenosis in the patients with the proximal form of AORPA remains to be further clarified.

In China, very few cases of AORPA were reported in recent decades $[19,20]$. Considering that China has the biggest population in the world, the number of reported Chinese cases with AORPA was far less than it should be. We believe that there are two main factors that

Table 2 The latest follow-up data of 6 patients

\begin{tabular}{lllllll}
\hline Variable & \multicolumn{7}{l}{ Patient Number } \\
\cline { 2 - 7 } & 1 & 2 & 3 & 4 & 5 & 6 \\
\hline Ross Modified Score & 1 & 1 & 0 & 2 & 1 & 2 \\
MPAP (mmHg) & 28 & 28 & 28 & 32 & 32 & 32 \\
Eject function & $78 \%$ & $69 \%$ & $67 \%$ & $64 \%$ & $71 \%$ & $68 \%$ \\
Pressure Gradient (mmHg) & 38 & 13 & 16 & 0 & 16 & 18 \\
Follow-up Period (months) & 26 & 25 & 23 & 14 & 5 & 2 \\
\hline
\end{tabular}

MPAP: Mean Pulmonary Artery Pressure 
contribute to this. First, the lack of a stable and advanced medical system especially in Chinese rural areas causes the misdiagnosis and limits surgical repair opportunities for AORPA. Second, financial constraints prevent referral of patients with AORPA to a better hospital. Although the development of the Chinese economy has greatly alleviated the situation, there are still many patients with complex congenital heart disease undiagnosed and untreated in early life.

\section{Conclusions}

Our team evaluated the surgical results for anomalous origin of the right pulmonary artery from the ascending aorta (AORPA). All 6 patients had the proximal form, and we believed direct implantation to be the optimal surgical strategy for patients with this form. There were no hospital or follow-up deaths. No cardiac failure was observed in all 6 patients during the follow-up, either. None of them required reoperation or reintervention. Carefully follow-up is necessary for all patients.

\section{Consent}

Written informed consent was obtained from the patient's guardian/parent/next of kin for the publication of thisreport and any accompanying images.

\section{Abbreviations}

AORPA: Anomalous origin of the right pulmonary artery from the ascending aorta; MPAP: Mean pulmonary artery pressure; PDA: Patent ductus arteriosus; TOF: Tetralogy of Fallot; ASD: Atrial septal defect; VSD: Ventricular septal defect; PA: Pulmonary artery; ICU: Intensive care unit; PFO: Patent foramen ovale; RPA: Right pulmonary artery; CPB time: Cardiopulmonary bypass time.

\section{Competing interests}

The authors declare that they have no competing interests.

\section{Authors' contributions}

LX collected the data. YFY wrote the manuscript. XL, LG, QW, CH, JFY, TLZ, ZSW and YFY participated in the design of the manuscript and they revised and reviewed the manuscript. All authors read and approved the final manuscript.

Received: 11 February 2015 Accepted: 29 June 2015

Published online: 11 July 2015

\section{References}

1. Dodo H, Alejos JC, Perloff JK, Laks H, Drinkwater DC, Williams RG. Anomalous origin of the left main pulmonary artery from the ascending aorta associated with DiGeorge syndrome. Am J Cardiol. 1995;75(17):1294-5.

2. Kajihara N, Imoto Y, Sakamoto M, Ochiai Y, Kan-o M, Joo K, et al. Surgical results of anomalous origin of the right pulmonary artery from the ascending aorta including reoperation for infrequent complications. Ann Thorac Surg. 2008;85(4):1407-11.

3. Kutsche LM, Van Mierop LH. Anomalous origin of a pulmonary artery from the ascending aorta: associated anomalies and pathogenesis. Am J Cardiol. 1988;61(10):850-6.

4. Keane JF, Maltz D, Bernhard WF, Corwin RD, Nadas AS. Anomalous origin of one pulmonary artery from the ascending aorta. Diagnostic, physiological and surgical considerations. Circulation. 1974;50(3):588-94.

5. Fontana GP, Spach MS, Effmann EL, Sabiston Jr DC. Origin of the right pulmonary artery from the ascending aorta. Ann Surg. 1987;206(1):102-13.

6. Ross RD, Bollinger RO, Pinsky WW. Grading the severity of congestive heart failure in infants. Pediatr Cardiol. 1992;13(2):72-5.
7. Reithmann C, Reber D, Kozlik-Feldmann R, Netz H, Pilz G, Welz A, et al. A post-receptor defect of adenylyl cyclase in severely failing myocardium from children with congenital heart disease. Eur J Pharmacol. 1997;330(1):79-86.

8. Patel RJ, Zakir RM, Sethi V, Patel JN, Apovian J, Alexander JC, et al. Unrepaired tetralogy of fallot with right hemitruncus in an adult: a rare case. Tex Heart Inst J. 2007;34(2):250-1.

9. Fong LV, Anderson RH, Siewers RD, Trento A, Park SC. Anomalous origin of one pulmonary artery from the ascending aorta: a review of echocardiographic, catheter, and morphological features. Br Heart J. 1989;62(5):389-95.

10. Abu-Sulaiman RM, Hashmi A, McCrindle BW, Williams WG, Freedom RM. Anomalous origin of one pulmonary artery from the ascending aorta: 36 years' experience from one centre. Cardiol Young. 1998;8(4):449-54.

11. Benatar A, Kinsley RH, Milner S, Dansky R, Hummel DA, Levin SE. Surgical correction for one pulmonary artery arising from ascending aorta-report of five cases. Int J Cardiol. 1987;16(3):249-55.

12. Penkoske PA, Castaneda AR, Fyler DC, Van Praagh R. Origin of pulmonary artery branch from ascending aorta. Primary surgical repair in infancy. J Thorac Cardiovasc Surg. 1983;85(4):537-45

13. Prifti $E$, Bonacchi M, Murzi B, Crucean A, Leacche $M$, Bernabei $M$, et al. Anomalous origin of the right pulmonary artery from the ascending aorta. J Card Surg. 2004;19(2):103-12.

14. Armer RM, Shumacker HB, Klatte EC. Origin of the right pulmonary artery from the ascending aorta. Report of a surgically corrected case. Circulation. 1961;24:662-8

15. Fucci C, di Carlo DC, Di Donato R, Marino B, Calcaterra G, Marcelletti C. Anomalous origin of the right pulmonary artery from the ascending aorta: repair without cardiopulmonary bypass. Int J Cardiol. 1989;23(3):309-13.

16. Nakamura Y, Yasui H, Kado H, Yonenaga K, Shiokawa Y, Tokunaga S. Anomalous origin of the right pulmonary artery from the ascending aorta. Ann Thorac Surg. 1991;52(6):1285-91.

17. Salaymeh KJ, Kimball TR, Manning PB. Anomalous pulmonary artery from the aorta via a patent ductus arteriosus: repair in a premature infant. Ann Thorac Surg. 2000;69(4):1259-61.

18. Peng EW, Shanmugam G, Macarthur KJ, Pollock JC. Ascending aortic origin of a branch pulmonary artery-surgical management and long-term outcome. Eur J Cardiothorac Surg. 2004;26(4):762-6.

19. He J, Li H, Li Y, Gui L, Mao X. Anomalous origin of the right pulmonary artery from the ascending aorta : Successful correction in an adult patient. Herz. 2015;40(2):311-3.

20. Liu Y, Cheng L, Qian X, Zhu H, Duan W, Yu S, et al. Surgical Correction of Anomalous Origin of One Pulmonary Artery Without Grafts in Infants. J Cardiac Surg. 2015;30(1):85-91.

\section{Submit your next manuscript to BioMed Central and take full advantage of:}

- Convenient online submission

- Thorough peer review

- No space constraints or color figure charges

- Immediate publication on acceptance

- Inclusion in PubMed, CAS, Scopus and Google Scholar

- Research which is freely available for redistribution 